\title{
In vitro Generation of Megakaryocytes and Platelets
}

\author{
Huicong Liu, Jiaqing Liu, Lingna Wang and Fangfang Zhu* \\ School of Biomedical Engineering, Shanghai Jiao Tong University, Shanghai, China
}

Platelets, the tiny anucleate cells responsible for stopping bleeding through thrombosis, are derived from hematopoietic stem cells through a series of differentiation steps. Thrombocytopenia, characterized by abnormally low blood platelet counts, may arise from cancer therapies, trauma, sepsis, as well as blood disorders, and could become a life-threatening problem. Platelet transfusion is the most effective strategy to treat thrombocytopenia, however, the source of platelets is in great shortage. Therefore, in vitro generation of platelets has become an important topic and numerous attempts have been made toward generating platelets from different types of cells, including hematopoietic stem cells, pluripotent stem cells, fibroblast cells, and adipose-derived cells. In this review, we will detail the efforts made to produce, in the in vitro culture,

OPEN ACCESS

Edited by:

Jianjun Zhou,

Tongji University, China

Reviewed by:

Gianandrea Pasquinelli, University of Bologna, Italy

Yongping Jiang,

Chinese Academy of Medical Sciences and Peking Union Medical

College, China

*Correspondence:

Fangfang Zhu zhuff@sjtu.edu.cn

Specialty section:

This article was submitted to

Stem Cell Research,

a section of the journal

Frontiers in Cell and Developmental

Biology

Received: 23 May 2021

Accepted: 26 July 2021

Published: 12 August 2021

Citation:

Liu H, Liu J, Wang L and Zhu F (2021) In vitro Generation of Megakaryocytes and Platelets. Front. Cell Dev. Biol. 9:713434. doi: 10.3389/fcell.2021.713434 platelets from these different cell types. Importantly, as transfusion medicine requires a huge number of platelets, we will highlight some studies on producing platelets on a large scale. Although new methods of gene manipulation, new culture conditions, new cytokines and chemical compounds have been introduced in platelet generation research since the first study of hematopoietic stem cell-derived platelets nearly 30 years ago, limited success has been achieved in obtaining truly mature and functional platelets in vitro, indicating the studies of platelets fall behind those of other blood cell types. This is possibly because megakaryocytes, which produce platelets, are very rare in blood and marrow. We have previously developed a platform to identify new extrinsic and intronic regulators for megakaryocytic lineage development, and in this review, we will also cover our effort on that. In summary, stem cell-based differentiation is a promising way of generating large-scale platelets to meet clinical needs, and continuous study of the cellular development of platelets will greatly facilitate this.

Keywords: platelet, megakaryocyte, hematopoietic stem cell, pluripotent stem cell, lineage reprogramming, transcription factor, histone deacetylase (HDAC), GABA

\section{INTRODUCTION}

Platelets, small and anucleate cells in the blood, are multifunctional and implicated in many pathophysiological processes, including hemostasis, thrombosis, vessel constriction and repair, and inflammations during host defense and tumor growth/metastasis (Harrison, 2005). Platelets, generated from hematopoietic stem cell-derived megakaryocytes, have a short lifespan of only 8-10 days (McArthur et al., 2018), and therefore in healthy persons, new platelets have to be produced constantly to maintain a normal level. Thrombocytopenia, defined by a platelet count of $<1.5 \times 10^{11} / \mathrm{L}$ in the blood, is not only commonly seen in some hematological diseases, for 
example, leukemia, bone marrow abnormalities, and hematopoietic aplastic anemia (Squires, 2015), but also may arise from multiple other conditions including connective tissue diseases, critical care medicine, hepatopathy, infectious illnesses, as well as cancer radiotherapy and chemotherapy (Robb and Begley, 1997). To reduce the mortality caused by bleeding in these situations, platelet transfusion has become an effective and irreplaceable treatment strategy.

Currently, platelets used in the clinic are provided solely through blood donations. With the rising population of hematological cancer patients and the development of clinical treatment options for various diseases, demands for platelets in transfusion medicine have been steadily growing in the aging society. However, blood donations have not been increased proportionally, therefore, the severe shortage of platelets has become a worldwide problem. To address this issue, researchers have been focusing on pursuing alternative strategies to obtain platelets. Since the first report of in vitro generation of platelets from hematopoietic stem cells by Choi et al. (1995) about 30 years ago, efforts have been made to derive, from in vitro culture, human platelets from different types of cells, including hematopoietic stem cells, human embryonic stem cells, human induced pluripotent stem cells, fibroblast cells, and adipose tissue-derived cells. Among all these sources, stem cells have attracted the most attention because they secure an unlimited supply. To date, existing protocols have been established by the ectopic expression of key transcription factors (TFs) which control megakaryocyte and platelet cell fate during development, by the activation or inhibition of external signals with cytokines or chemical compounds, as well as by the co-culture with stromal cells or in $3 \mathrm{D}$ conditions to provide an environment similar to that during embryonic development. The ability to regenerate platelets in vitro would address the urgent and unmet needs of platelet supply in clinics and provide a promising way to solve the life-threatening bleeding problem in different diseases. Besides, these methods also have significant advantages over the current donor-dependent program, in terms of variations between donors, number of cells that could be obtained, risk of bacteria and virus contamination, cell viability, and storage, etc. Figure 1 shows how different cell sources could be used in vitro for platelet-required clinical applications.

However, only limited success has been achieved so far in producing truly mature and functional platelets from these in vitro cultures. With various differentiation methods, platelets could be generated, and they are phenotypically similar to plasma-derived platelets, however, the in vivo functions of these platelets were either not tested or not as good as plasma-derived platelets. More importantly, their lifespan is much shorter than that of primary platelets. Therefore, platelet differentiation protocols require further optimization. One of the possible reasons why in vitro derived platelets are not as expected is our lack of knowledge on how megakaryocyte and platelet generation from hematopoietic stem cells is precisely regulated during development. Megakaryocytes in the blood are very rare, and in bone marrow, they represent only $0.01 \%$ of all nucleated cells (Nakeff and Maat, 1974), which makes it difficult to isolate and culture these cells, and therefore, the research on megakaryocyte generation and differentiation falls far behind that of other hematopoietic cell types. We have described the identification of new intrinsic and extrinsic regulators for megakaryocyte development with an established platform that is designed to identify the hematopoietic regulatory network by combining the Gene Expression Commons (GeXC), which profiles the absolute expression of any gene on the microarray (Seita et al., 2012), CRISPR/Cas9 mediated gene knockout screening and lentivirusmediated gene overexpression.

In this review, we will first summarize the existing research progress on in vitro generation of platelets from stem cells and other cell types and then discuss the promising solutions to hit the final goal of generating large-scale mature platelets in vitro for basic research and clinical applications.

\section{CELL SOURCES FOR IN VITRO MEGAKARYOCYTE AND PLATELET GENERATION}

Different cells have been used as the starting materials to derive megakaryocytes and platelets in vitro, and these cells belong to two types: embryonic or adult stem cells including hematopoietic stem cells and human pluripotent stem cells which can directly differentiate into megakaryocytes and platelets naturally, while the other cell types including fibroblasts and adipose tissuederived cells that are not its natural progenitors and require a conversion of cell fates from one to another. Stem cells as the cell source for platelets usually have the advantages in terms of scalability, ease of genetic modification, and platelet functions. However, different stem cells have their unique characteristics, and may require different methods to be directed to generate platelets. Table 1 summarizes current progress in platelet production in vitro from these different types of cells, which covers differentiation methods, efficiency, etc., and although all groups successfully characterized the generated megakaryocytes and platelets with various in vitro assays, functional tests in animal models (mouse, rabbit, etc.) were performed in only one third of these studies. Of note, Guan et al. (2017) not only demonstrated generated human megakaryocytes could engraft in mice and produce functional platelets, but also showed platelet recovery in non-human primates that were transplanted with autologous megakaryocytes, bringing one step closer to the clinical applications of human platelet transfusion.

\section{Generation of Platelets From Hematopoietic Stem Cells}

Hematopoietic stem cells (HSCs), which could be found in bone marrow (BM), peripheral blood (PB), and cord blood (CB) after birth, continuously divide to provide more hematopoietic stem and progenitor cells to balance self-renewal and differentiation. Through multiple steps, HSCs differentiate into multipotent progenitors (MPPs), common myeloid progenitors (CMPs), megakaryocyte-erythroid progenitors (MEPs), megakaryocyte progenitors (MkPs), and then megakaryocytes (MKs), which finally mature and produce 


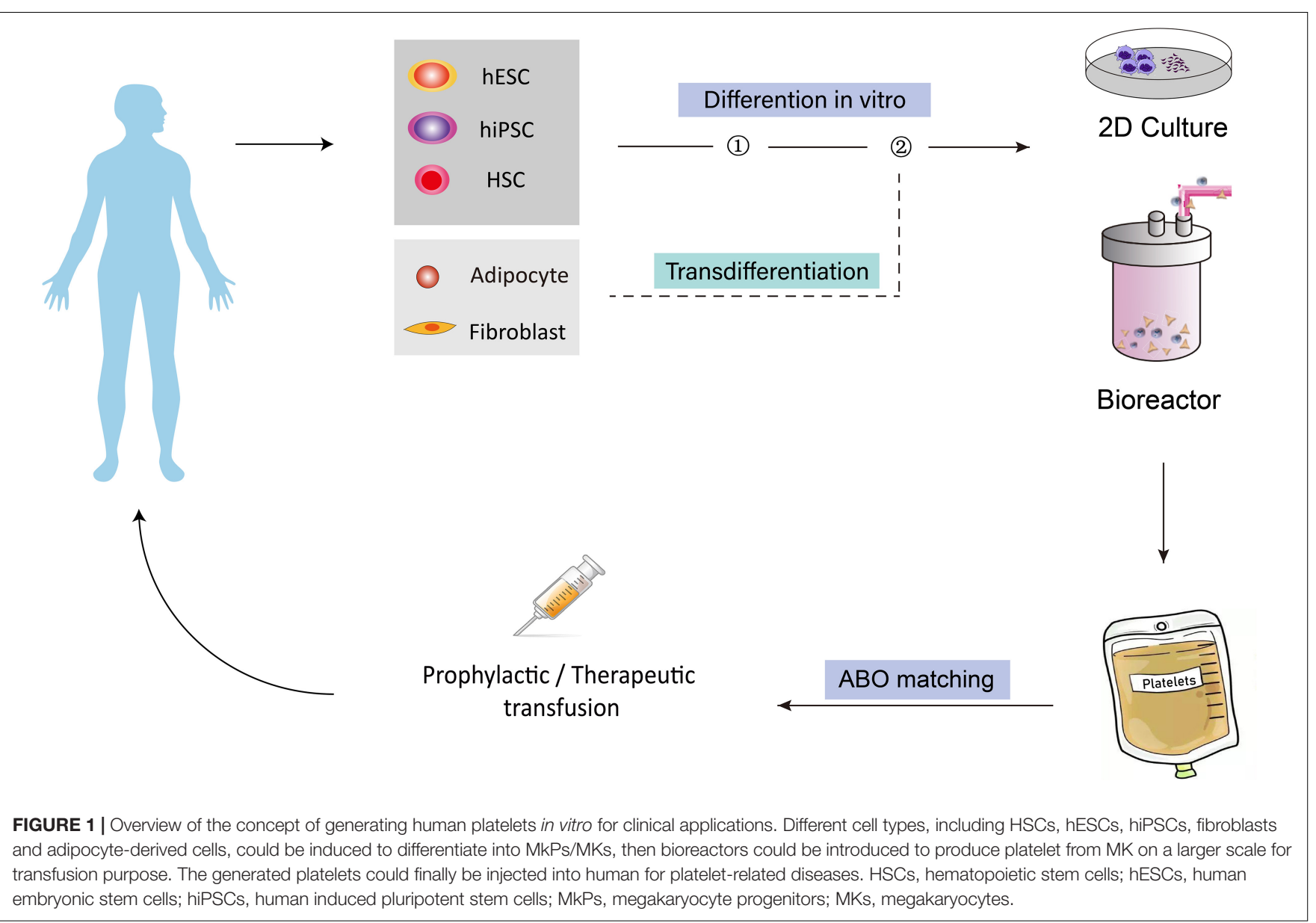

functional platelets (Seita and Weissman, 2010; Machlus and Italiano, 2013). Therefore, the generation of HSC-derived platelets seems to be a natural process, and the earliest attempts to create platelets in vitro were using CD34-enriched HSCs as the starting materials. Choi et al. (1995) first described a method in which isolated HSCs from PB were cultured in conditions supplemented with human and aplastic canine serum to induce MK differentiation. Aplastic canine serum was then removed from the culture medium in which plasma factors from human serum promoted MK differentiation to platelets, which exhibited a similar ultrastructure to platelets isolated from plasma and could be aggregated after platelet agonist adenosine diphosphate (ADP) treatment. However, the differentiation efficiency is very low, with only $3 \times 10^{6}$ mature MKs obtained from one leukapheresis unit, and only about $40 \%$ MKs could generate platelets upon further differentiation (Choi et al., 1995).

Various optimizations were later tried to improve the differentiation efficiency. Norol et al. (1998) searched for cytokines that could stimulate the generation of $\mathrm{MKs}$ and platelets from HSCs. They tested the functions of megakaryocyte growth and development factor (MGDF, now commonly known as thrombopoietin, TPO), the ligand for $\mathrm{Mpl}$, either alone or in various combinations with stem cell factor (SCF), interleukin-3 (IL-3), and IL-6. They found both TPO alone and its combination with these three cytokines accelerated MK differentiation, while TPO alone was able to promote platelet production by 10 -fold, highlighting the critical role of TPO in MK differentiation, maturation, and platelet generation (Norol et al., 1998). Currently, TPO is regarded as one of the most important cytokines in megakaryocytopoiesis and thrombopoiesis. Proulx et al. (2004), in an interesting study, showed the unexpected effect of elevated temperature on differentiation of HSCs to MKcommitted cells. Compared to those at $37^{\circ} \mathrm{C}$, the differentiation cultures maintained at $39^{\circ} \mathrm{C}$ promoted the proliferation and differentiation efficiency of HSCs, accelerated MK maturation by 3-4 days, and improved platelets output by more than 15-fold (Proulx et al., 2004). Later, the 3D culture method, specifically the roller-bottle cell culture system, was also found to be able to improve the efficiency of platelet generation from CB HSCs by a few folds, compared with the routinely used static culture condition, either in a small research scale (Yang et al., 2016) or in a Good Manufacturing Practice (GMP) standard culture (Guan et al., 2020).

To fulfill transfusion purposes, attempts were also made to generate platelets on a large scale. Matsunaga et al. (2006) reported a 33-day three-phase culture system using HSCs isolated from $\mathrm{CB}$. By combining co-culture with telomerase gene-transduced human stromal cells for MK differentiation and 
TABLE 1 | Summary of current methods for in vitro generation of megakaryocytes and platelets from different type of cells.

\begin{tabular}{|c|c|c|c|c|c|c|c|c|c|}
\hline Reference & $\begin{array}{l}\text { Cell } \\
\text { source }\end{array}$ & $\begin{array}{l}\text { Culture } \\
\text { condition }\end{array}$ & $\begin{array}{l}\text { Differentiation } \\
\text { steps }\end{array}$ & Cytokines & $\begin{array}{l}\text { Stromal cell } \\
\text { coculture }\end{array}$ & $\begin{array}{c}\text { Gene } \\
\text { editing }\end{array}$ & Large scale & Efficiency & $\begin{array}{l}\text { In vivo } \\
\text { function } \\
\text { evaluation }\end{array}$ \\
\hline $\begin{array}{l}\text { Choi et al., } \\
1995\end{array}$ & $\begin{array}{l}\text { CD34+ } \\
\text { HSC }\end{array}$ & $2 \mathrm{D}$ & HSC-MK-PLT & N/A & N/A & $\mathrm{N} / \mathrm{A}$ & No & $\begin{array}{l}2.1 \mathrm{MKs} \text { per } \\
\text { HSC }\end{array}$ & N/A \\
\hline $\begin{array}{l}\text { Norol et al., } \\
1998\end{array}$ & & $2 \mathrm{D}$ & $\begin{array}{c}\text { HSC-MkP-MK- } \\
\text { PLT }\end{array}$ & $\begin{array}{l}\text { TPO, SCF, IL-3, } \\
\text { IL-6 }\end{array}$ & N/A & $\mathrm{N} / \mathrm{A}$ & No & $\begin{array}{l}4.6 \mathrm{MKs} \text { per } \\
\text { HSC }\end{array}$ & $\mathrm{N} / \mathrm{A}$ \\
\hline $\begin{array}{l}\text { Proulx } \\
\text { et al., } 2004\end{array}$ & & $2 \mathrm{D}$ & HSC-MK-PLT & $\begin{array}{l}\text { TPO, SCF, IL-6, } \\
\text { FL }\end{array}$ & $\mathrm{N} / \mathrm{A}$ & $\mathrm{N} / \mathrm{A}$ & No & $\begin{array}{l}120 \text { PLTs per } \\
\text { seeded cells }\end{array}$ & $\mathrm{N} / \mathrm{A}$ \\
\hline $\begin{array}{l}\text { Matsunaga } \\
\text { et al., } 2006\end{array}$ & & $2 \mathrm{D}$ & HSC-MK-PLT & $\begin{array}{l}\text { TPO, SCF, IL-3, } \\
\text { FL, IL-6,IL-11, } \\
\text { IL-1 } \beta, \text { SDF-1 } \alpha \text {, } \\
\text { FGF-4, PDGF }\end{array}$ & hTERT & N/A & Yes & $\begin{array}{l}3.36 \times 10^{4} \\
\text { PLTs per HSC }\end{array}$ & N/A \\
\hline $\begin{array}{l}\text { Yang et al., } \\
2016\end{array}$ & & $\begin{array}{l}\text { Rotary } \\
\text { vessel }\end{array}$ & HSC-MK-PLT & $\begin{array}{l}\text { TPO, SCF, IL-3, } \\
\text { IL-11 }\end{array}$ & N/A & $\mathrm{N} / \mathrm{A}$ & Yes & $\begin{array}{l}\sim 1.9 \times 10^{3} \\
\text { PLTs per HSC }\end{array}$ & N/A \\
\hline $\begin{array}{l}\text { Guan et al., } \\
2017\end{array}$ & & $2 \mathrm{D}$ & HSC-MK & $\begin{array}{l}\text { SCF, FL, TPO, } \\
\text { IL-3, IL-6, IL-11, } \\
\text { GM-CSF, SR1 }\end{array}$ & $\mathrm{N} / \mathrm{A}$ & $\mathrm{N} / \mathrm{A}$ & No & $\begin{array}{l}1 \times 10^{4} \mathrm{MKs} \\
\text { per HSC }\end{array}$ & $\begin{array}{l}\text { MKs } \\
\text { produced } \\
\text { functional } \\
\text { PLTs in mice } \\
\text { and monkeys }\end{array}$ \\
\hline $\begin{array}{l}\text { Guan et al., } \\
2020\end{array}$ & & $\begin{array}{l}\text { Roller- } \\
\text { bottle }\end{array}$ & HSC-MK & $\begin{array}{l}\text { TPO, SCF, IL-6, } \\
\text { SR1, C433, VPA }\end{array}$ & N/A & $\mathrm{N} / \mathrm{A}$ & Yes & $\begin{array}{l}2 \times 10^{4} \mathrm{MKs} \\
\text { per HSC }\end{array}$ & $\begin{array}{l}\text { MKs } \\
\text { produced } \\
\text { functional } \\
\text { PLTs in mice }\end{array}$ \\
\hline $\begin{array}{l}\text { Gaur et al., } \\
2006\end{array}$ & hESC & $2 \mathrm{D}$ & hESC-MK-PLT & TPO, bFGF & OP9, MEF & $\mathrm{N} / \mathrm{A}$ & No & $\begin{array}{l}0.05-0.2 \mathrm{MK} \\
\text { per hESC }\end{array}$ & N/A \\
\hline $\begin{array}{l}\text { Takayama } \\
\text { et al., } 2008\end{array}$ & & $2 \mathrm{D}$ & $\begin{array}{c}\text { hESC-HPC- } \\
\text { MK-PLT }\end{array}$ & $\begin{array}{l}\text { TPO, IGF-II, } \\
\text { VEGF, bFGF, } \\
\text { heparin, SCF, } \\
\text { PIGF }\end{array}$ & $\begin{array}{c}\text { OP9, } \\
\text { C3H10T1/2 }\end{array}$ & $\mathrm{N} / \mathrm{A}$ & No & $\begin{array}{l}48 \text { PLTs per } \\
\text { hESC }\end{array}$ & $\mathrm{N} / \mathrm{A}$ \\
\hline $\begin{array}{l}\text { Lu et al., } \\
2011\end{array}$ & & $2 \mathrm{D}$ & hESC-MK-PLT & $\begin{array}{l}\text { IL-6, IL-9, IL-11, } \\
\text { bFGF, VEGF, } \\
\text { TPO, SCF }\end{array}$ & $\begin{array}{c}\text { OP9, } \\
\text { C3H10T1/2 }\end{array}$ & N/A & Yes & $\begin{array}{l}5.5 \times 10^{3} \text { PLTS } \\
\text { per hESC }\end{array}$ & $\begin{array}{l}\text { PLTs } \\
\text { contributed } \\
\text { to thrombi in } \\
\text { mice }\end{array}$ \\
\hline $\begin{array}{l}\text { Pick et al., } \\
2013\end{array}$ & & $2 \mathrm{D}$ & $\begin{array}{c}\text { hESC-MkP- } \\
\text { MK-PLT }\end{array}$ & $\begin{array}{l}\text { TPO, SCF, IL-3, } \\
\text { FGF2, VEGF, } \\
\text { BMP-4 }\end{array}$ & MEF & N/A & No & $\begin{array}{l}0.25-1.6 \mathrm{MkPs} \\
\text { per } 10^{3} \mathrm{hESCs}\end{array}$ & $\mathrm{N} / \mathrm{A}$ \\
\hline $\begin{array}{l}\text { Takayama } \\
\text { et al., } 2010\end{array}$ & hiPSC & $2 \mathrm{D}$ & $\begin{array}{l}\text { hiPSC-HPC- } \\
\text { MK-PLT }\end{array}$ & SCF, TPO, FL & C3H10T1/2 & c-MYC & No & $\begin{array}{l}20 \text { PLTs per } \\
\text { hiPSC }\end{array}$ & $\begin{array}{l}\text { PLTs } \\
\text { contributed } \\
\text { to thrombi in } \\
\text { mice }\end{array}$ \\
\hline $\begin{array}{l}\text { Nakamura } \\
\text { et al., } 2014\end{array}$ & & $2 \mathrm{D}$ & $\begin{array}{l}\text { hiPSC-HPC- } \\
\text { imMKCL-MK- } \\
\text { PLT }\end{array}$ & TPO, SCF & С3H10T1/2 & $\begin{array}{l}\text { C-MYC, } \\
\text { BMl1, } \\
\text { BCL-XL }\end{array}$ & No & $\begin{array}{l}250 \mathrm{MKs} \text { per } \\
\text { imMKCL }\end{array}$ & $\begin{array}{l}\text { PLTs } \\
\text { contributed } \\
\text { to thrombi in } \\
\text { mice }\end{array}$ \\
\hline $\begin{array}{l}\text { Ito et al., } \\
2018\end{array}$ & & Bioreactor & $\begin{array}{c}\text { hiPSC- } \\
\text { imMKCL-MK- } \\
\text { PLT }\end{array}$ & $\begin{array}{l}\text { SCF, TA-316, } \\
\text { Y27632/Y39983, } \\
\text { SR1, KP-457, } \\
\text { GNF-351 }\end{array}$ & С3H10T1/2 & $\begin{array}{l}\text { C-MYC, } \\
\text { BMI1, } \\
\text { BCL-XL }\end{array}$ & Yes & $\begin{array}{l}\text { 70-80 PLTs per } \\
\text { hiPSC }\end{array}$ & $\begin{array}{l}\text { PLTs } \\
\text { contributed } \\
\text { to } \\
\text { hemostasis in } \\
\text { mice and } \\
\text { rabbits }\end{array}$ \\
\hline $\begin{array}{l}\text { Feng et al., } \\
2014\end{array}$ & & $2 \mathrm{D}$ & $\begin{array}{l}\text { hiPSC-MkP- } \\
\text { MK-PLT }\end{array}$ & $\begin{array}{l}\text { TPO, SCF, IL-3, } \\
\text { IL-6, IL-9, ACF, } \\
\text { FL, APEL, } \\
\text { BMP-4, VEGF, } \\
\text { bFGF }\end{array}$ & $\mathrm{N} / \mathrm{A}$ & $\mathrm{B} 2 \mathrm{M} \mathrm{KO}$ & No & $\begin{array}{l}\sim 16 \mathrm{MkPs} \text { per } \\
\text { iPSC }\end{array}$ & $\begin{array}{l}\text { PLTs } \\
\text { contributed } \\
\text { to thrombi in } \\
\text { mice }\end{array}$ \\
\hline $\begin{array}{l}\text { Moreau } \\
\text { et al., } 2016\end{array}$ & & $2 \mathrm{D}$ & $\begin{array}{l}\text { hiPSC-hPSC- } \\
\text { MK }\end{array}$ & $\begin{array}{l}\text { TPO, IL-1 } \beta, \text { SCF, } \\
\text { BMP4, Y-27632, } \\
\text { FGF2, LY-294002 }\end{array}$ & $N / A$ & $\begin{array}{c}\text { GATA1, } \\
\text { FLI1, TAL1 }\end{array}$ & Yes & $\begin{array}{l}2 \times 10^{5} \mathrm{MKs} \\
\text { per hiPSC }\end{array}$ & N/A \\
\hline
\end{tabular}


TABLE 1 | Continued

\begin{tabular}{|c|c|c|c|c|c|c|c|c|c|}
\hline Reference & $\begin{array}{l}\text { Cell } \\
\text { source }\end{array}$ & $\begin{array}{l}\text { Culture } \\
\text { condition }\end{array}$ & $\begin{array}{l}\text { Differentiation } \\
\text { steps }\end{array}$ & Cytokines & $\begin{array}{l}\text { Stromal cell } \\
\text { coculture }\end{array}$ & $\begin{array}{l}\text { Gene } \\
\text { editing }\end{array}$ & Large scale & Efficiency & $\begin{array}{l}\text { In vivo } \\
\text { function } \\
\text { evaluation }\end{array}$ \\
\hline $\begin{array}{l}\text { Eicke et al., } \\
2018\end{array}$ & & Bioreactor & hiPSC-MK-PLT & $\begin{array}{l}\text { VEGF, BMP4, } \\
\text { TPO, SCF, IL-3, } \\
\text { Y27632 }\end{array}$ & N/A & $\mathrm{N} / \mathrm{A}$ & Yes & $\begin{array}{l}29.9 \text { MKs per } \\
\text { hiPSC }\end{array}$ & $\begin{array}{l}\text { MKs } \\
\text { produced } \\
\text { PLTs in mice }\end{array}$ \\
\hline $\begin{array}{l}\text { Norbnop } \\
\text { et al., } 2020\end{array}$ & & $2 \mathrm{D}$ & $\begin{array}{l}\text { hiPSC-HPC- } \\
\text { MK-PLT }\end{array}$ & $\begin{array}{l}\text { VEGF, TPO, SCF, } \\
\text { heparin }\end{array}$ & OP9 & $\mathrm{B} 2 \mathrm{M} \mathrm{KO}$ & No & $\mathrm{N} / \mathrm{A}$ & $\begin{array}{l}\text { MKs } \\
\text { produced } \\
\text { PLTs in mice }\end{array}$ \\
\hline $\begin{array}{l}\text { Ono et al., } \\
2012\end{array}$ & Fibroblast & $2 \mathrm{D}$ & $\begin{array}{c}\text { Fibroblast-iMK- } \\
\text { PLT }\end{array}$ & $\mathrm{N} / \mathrm{A}$ & N/A & $\begin{array}{l}\text { p45NF-E2, } \\
\text { Maf G, } \\
\text { MafK, } \\
\text { CEBP } \alpha\end{array}$ & No & $\begin{array}{l}0.04-0.05 \mathrm{iMK} \\
\text { per fibroblast }\end{array}$ & $\begin{array}{l}\text { MKs } \\
\text { produced } \\
\text { PLTs in mice }\end{array}$ \\
\hline $\begin{array}{l}\text { Pulecio } \\
\text { et al., } 2016\end{array}$ & & $2 \mathrm{D}$ & $\begin{array}{l}\text { Fibroblast- } \\
\text { iMkP-MK-PLTs }\end{array}$ & $\begin{array}{l}\text { TPO, IL-3, IL-6, } \\
\text { IL-9, SCF }\end{array}$ & $\mathrm{N} / \mathrm{A}$ & $\begin{array}{l}\text { GATA1, } \\
\text { GATA2, } \\
\text { TAL1, } \\
\text { LMO2, } \\
\text { c-MYC, } \\
\text { RUNX1 }\end{array}$ & No & $\mathrm{N} / \mathrm{A}$ & $\begin{array}{l}\text { MkP } \\
\text { produced } \\
\text { MKs and } \\
\text { PLTs in mice }\end{array}$ \\
\hline $\begin{array}{l}\text { Matsubara } \\
\text { et al., } 2009\end{array}$ & Adipocyte & $2 \mathrm{D}$ & $\begin{array}{c}\text { Adipocyte-MK- } \\
\text { PLT }\end{array}$ & $\begin{array}{l}\text { LDL, TPO, dNTP, } \\
\text { Insulin, Transferrin }\end{array}$ & $\mathrm{N} / \mathrm{A}$ & $\mathrm{N} / \mathrm{A}$ & No & $\begin{array}{l}0.2 \mathrm{MK} \text { and } \\
0.015 \mathrm{PLT} \text { per } \\
\text { adipocyte } \\
\text { precursor cell }\end{array}$ & $\mathrm{N} / \mathrm{A}$ \\
\hline $\begin{array}{l}\text { Tozawa } \\
\text { et al., } 2019\end{array}$ & & Bioreactor & $\begin{array}{c}\text { Adipose-ASCL- } \\
\text { MK-PLT }\end{array}$ & $\begin{array}{l}\text { Transferrin, LDL, } \\
\text { Insulin, dNTP, } \\
\text { TPO }\end{array}$ & $\mathrm{N} / \mathrm{A}$ & $\mathrm{N} / \mathrm{A}$ & Yes & $\begin{array}{l}0.42 \text { PLT per } \\
\text { ASCL }\end{array}$ & $\begin{array}{l}\text { PLTs survived } \\
\text { in mice }\end{array}$ \\
\hline
\end{tabular}

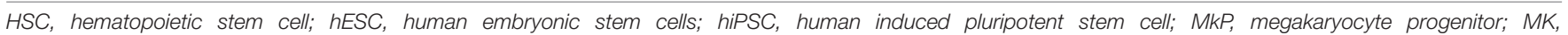
megakaryocyte; PLT, platelet.

expansion, and liquid culture medium for platelet production, they were able to obtain $1.26-1.68 \times 10^{11}$ platelets from 1 unit of $\mathrm{CB}$ (which contains $3-5 \times 10^{6} \mathrm{CD} 34^{+}$HSCs). These platelets exhibited features similar to those from plasma in both morphology and in vitro functions, including ADP-induced aggregation (Matsunaga et al., 2006).

However, despite all the current progress, the biggest challenge of producing platelets from HSCs is still the low differentiation efficiency and the difficulty of large-scale production in a timeand cost-efficient manner. Besides, there is no detailed analysis of the production of each progenitor population (CMPs, EPs, and MkPs) during the differentiation process, which led to the incomplete establishment of the differentiation path from HSCs to platelets.

\section{Generation of Platelets From Human Pluripotent Stem Cells}

Human pluripotent stem cells (hPSCs) comprise human embryonic stem cells (hESCs) and the recently discovered human induced pluripotent stem cells (hiPSCs). hPSCs could proliferate (self-renew) infinitely in vitro, and under specific conditions, they can differentiate into any cell type of the human body. Therefore, hPSCs could serve as an unlimited source for platelet production in vitro.

\section{Generation of hESC-Derived Platelets}

Thomson et al. (1998) reported the derivation of the first hESCs from the inner cell mass of blastocyst-stage human embryos, opening the door for platelet differentiation from hESCs. Gaur et al. (2006) established an OP9 stromal cell co-culture system to increase MK production from hESCs, while the yield was unsatisfactory (less than $1 \mathrm{MK}$ produced per 10 input hESCs) and no release of platelets was demonstrated. Takayama et al. (2008) further refined the scheme, in which hESCs were co-cultured with either C3H10T1/2 or OP9 stromal cells and supplemented with human vascular endothelial growth factor (VEGF) to promote the emergence of sac-lick hematopoietic progenitors, which were then further differentiated into MKs and platelets by adding TPO. The platelets displayed activation in response to ADP. This study showed that adding factors that promote mesoderm differentiation from hESCs will eventually benefit the MK and platelet generation. However, MKs generated in this system produced very few platelets (Takayama et al., 2008). Later, Lu et al. (2011) described a more competent method to obtain functional MKs and platelets from hESCs on a large scale, in which they isolated hESC-derived early hematopoietic progenitor cells, the hemangioblasts/blast cells, for further differentiation into MK lineage cells through coculture with OP9. They were able to generate over $100 \mathrm{CD}_{11} \mathrm{a}^{+} \mathrm{MKs}$ per hESC, an efficiency much higher than the previous $0.05-0.2 \mathrm{MKs}$ and 2-5 MKs as reported by Gaur et al. (2006) and Takayama et al. (2008), respectively. After being transplanted into a mouse model, these platelets form thrombi at the sites of injury, which is the first report demonstrating the in vivo function of platelets derived from hESCs. However, only fewer than 7 platelets were produced from each hESC-derived MK with this method (Lu et al., 2011). A serum- and feeder-free culture system through embryoid bodies (EBs) differentiation was also established, moving one 
step forward toward using hESC-derived platelets for transfusion medicine, though the differentiation efficiency is very low, with only 100-800 MK-containing cell colonies obtained per 100,000 sorted CD41a+ cells derived from hESCs (Pick et al., 2013).

These studies above suggest that hESC-derived platelet production is feasible.

\section{Generation of hiPSC-Derived Platelets}

Human induced pluripotent stem cells possess similar selfrenewal capacity and multipotency to hESCs and could be generated from somatic cells of any individual by overexpression of the TF combinations OCT3/4, SOX2, KLF4, and c-MYC (OSKM) or OCT3/4, SOX2, NANOG, and LIN28 (OSNL) (Takahashi et al., 2007; Yu et al., 2007), which is a breakthrough in the stem cell field. Therefore, hiPSCs represent another promising unlimited source to obtain platelets without the risk of immune rejection, particularly for patients with a rare HLA, and ethical concerns of embryo destruction related to hESCs. Takayama et al. (2010) first demonstrated OSKM hiPSCs could give rise to $\mathrm{CD} 41 \mathrm{a}^{+} \mathrm{CD} 42 \mathrm{~b}^{+}$platelets. They co-cultured hiPSCs with mouse cell line C3H10T1/2 for differentiation into hematopoietic progenitors, which were subsequently cultured in MK differentiation medium to produce platelets. In vivo imaging revealed that these $\mathrm{CD}_{4} 2 \mathrm{~b}^{+}$platelets were present in thrombi after laser-induced vessel wall injury. Importantly, they showed that c-MYC promoted megakaryopoiesis in the early stage of differentiation but later inhibited thrombopoiesis, indicating complicated roles c-MYC is playing in this differentiation process (Takayama et al., 2010). Nakamura et al. (2014) developed inducible imMKCLs cell lines to improve the consistency and efficiency of platelet generation from hiPSCs. The imMKCLs cell lines are immortalized megakaryocytic cell lines which were differentiated from hiPSCs by inducible overexpression of c-MYC, BMI1, and BCL-XL through the Tet-on system, and then the expression of these three genes would be shut down when further differentiation of imMKCLs into platelets is needed. The imMKCLs could be expanded in vitro for 4-5 months, after which they could still be differentiated into platelets that are similar to those isolated from blood (Nakamura et al., 2014). In 2018, turbulence, which mimics the shear stress of blood and helps cut megakaryocytes into small platelets, was introduced by Ito et al. (2018) on a largescale generation of platelets from hiPSCs. They established a $3 \mathrm{D}$ differentiation system in which each hiPSC-derived MK generated 70-80 platelets, almost a 20-fold increase compared with previous reports, although it is still much less than that of $10^{4}$ platelets per megakaryocyte in the human body (Machlus and Italiano, 2013). Nevertheless, they eventually collected 100 billion platelets from hiPSC-MKs in an 8L turbulencecontrollable bioreactor, which represents a breakthrough for in vitro generation of platelet on a clinical scale for transfusion medicine (Ito et al., 2018).

Besides, other methods were also developed to induce the generation of platelets from hiPSCs. These methods either utilize stepwise differentiation from hiPSCs to early hematopoietic progenitors, then to MKs and finally to platelets, by using different cytokine combinations and culture media (Feng et al., 2014), or applied the microcarrier beads assisted stirred bioreactors to promote MK generation (Eicke et al., 2018), or rely on ectopic expression of key MK TFs GATA1, FLI1, and TAL1 in hiPSCs to directly promote platelet generation (Moreau et al., 2016). $2 \times 10^{11}$ MKs releasing $1 \times 10^{12}$ platelets - the equivalent of 3 transfusion units - could be obtained from only $1 \times 10^{6}$ input hiPSCs (Moreau et al., 2016). Furthermore, by knocking out the $\beta 2$-microglobulin gene, several groups have generated platelets without major histocompatibility antigens (HLA), which theoretically does not require additional HLA-match and does not cause immune rejection in clinical applications (Feng et al., 2014; Norbnop et al., 2020; Suzuki et al., 2020). Therefore, the application of hiPSCbased technology could potentially yield a consistent supply of HLA- and/or HPA-matched or even autologous platelets for clinical applications.

\section{Generation of Platelets From Other Cell Types}

Besides all studies described above to use various stem cells as the starting materials for platelet in vitro production, other cell types have also been used to generate megakaryocytes and platelets. However, the efficiency is low, and it is still far away from a practically feasible clinical implementation for platelet transfusion. Alternatively, they can be used for in vitro disease modeling and drug screening purposes for plateletrelated disorders.

\section{Generation of Fibroblast-Derived Platelets}

Transdifferentiation, also known as lineage reprogramming, was recognized as the direct conversion from one mature cell type to another. After the generation of hiPSCs from fibroblasts by overexpression of OSKM or OSNL, fibroblasts or other mature cells have been successfully converted to many different types of cells, such as neurons, cardiomyocytes, hepatocytes, etc. (Wang et al., 2021). Therefore, researchers have also attempted and accomplished, through overexpression of TFs critical for megakaryocytic lineage development, the direct conversion of fibroblasts to MKs, which could further produce platelets in vitro or in vivo after transplantation into mice. In one study, 3T3 fibroblast cell line and adult human dermal fibroblasts could be transdifferentiated into induced megakaryocytes (iMKs) through the overexpression of p45NFE2 and its binding proteins MafG and MafK (Ono et al., 2012). iMKs could further produce $\mathrm{CD} 41^{+}$platelets which were shown to be involved in thrombosis on the collagen-coated chip in vitro. However, the conversion efficiency is pretty low, and they only obtained $8-10 \times 10^{5}$ iMKs from $20 \times 10^{6}$ fibroblasts, indicating further optimization is required. Pulecio et al. (2016), in a previous study, identified a set of TFs GATA1, TAL-1, LMO2, and c-MYC (GTLM) that was able to convert fibroblast cells into EPs in the presence of erythropoietin (EPO). As EPs and MkPs are both derived from MEPs during development, they may share some core transcriptional regulators. Indeed, in a later study, they successfully generated MkPs from human fibroblasts by adding TFs GATA2 and RUNX1 to the GTLM combo (Pulecio et al., 2016). These MkPs could 
further differentiate and produce platelets in vitro as well as generate $\mathrm{CD} 41^{+} / \mathrm{CD} 42^{+}$platelets in vivo after transplantation into immunocompromised mice. This direct conversion to $\mathrm{MkPs}$ takes only 12 days and the $\mathrm{CD} 41^{+} / \mathrm{CD} 45^{+}$cells appear in $8 \%$ cell population. Importantly, they also showed in a Fanconi Anemia patient which has extremely low HSCs and frequent thrombocytopenia, that fibroblast cells could be isolated and in vitro gene-corrected, and then directly converted to generate healthy megakaryocytes and platelets.

\section{Generation of Adipose Tissue Cell-Derived Platelets}

Matsubara et al. (2009) have been trying to study the capacity of adipose tissue-derived cells in differentiating into MKs and platelets. In 2009, they first showed that megakaryocytes and platelets could be generated from human subcutaneous adipose tissues (Matsubara et al., 2009). Later, to further increase the differentiation efficiency, they generated an adipose tissuederived mesenchymal stem cell line (ASCL) from adipose-derived stromal cells. As the starting materials, these ASCL cells were able to proliferate for more than 2 months in vitro, and upon differentiation, these cells could generate platelets, which express typical platelet cell surface markers and could be activated by ADP. In the end, they were able to obtain one platelet from one starting ASCL (Tozawa et al., 2019).

\section{REGULATORY NETWORK OF MEGAKARYOCYTE DEVELOPMENT}

Despite all current progress, the generation of truly mature and functional platelets from in vitro cultures was demonstrated in few studies, and one possible reason is, the percentage of MKs in bone marrow is very low (about $0.01 \%$ of all nucleated cells) (Nakeff and Maat, 1974), therefore, although MKs were discovered over 100 years ago, it is very difficult to study their development and biology. So far, researchers have been focusing on the study of internal and external factors that affect the fate of megakaryocytic lineage cells. The external factors are exogenous signal transduction and microenvironment, and internal factors are mainly TFs and epigenetic regulators. To date, only a few TFs have been reported to be involved in this process, including GATA1 (Crispino and Horwitz, 2017), FLI1 (Li et al., 2015), MEIS1 (Zeddies et al., 2014), RUNX1 (Goldfarb, 2009), and SCL (Robb and Begley, 1997). Not surprisingly, some of these genes, including RUNX1, ERG and MEIS1, and TPO-encoding gene Thrombopoietin have all been demonstrated to be involved in hESC in vitro differentiation into MKs and platelets ( $\mathrm{Tu}$ et al., 2017; Wang et al., 2018; Zhang et al., 2018), indicating that studies in $\mathrm{MK}$ regulators will eventually help establish methods to drive platelet in vitro generation.

Our laboratory is devoted to discovering more TFs and mapping the regulatory network to understand the decisionmaking factors during platelet development (Zhu et al., 2018). To identify the regulators for HSC differentiation to MkPs, the immediate precursor cells for MKs and platelets, we applied Gene Expression Commons (GeXC), a platform developed in Irving Weissman's laboratory at Stanford University (Seita et al., 2012), to get the candidate gene list, in which these genes have high expression level in MkPs but low in EPs and MEPs, a common progenitor for MkPs and EPs. This expression pattern indicates that genes in this list may play a role in $\mathrm{MkP}$ differentiation. To address this hypothesis, we deleted these candidate genes separately in HSCs using CRISPR/Cas9 and found that the knockout of some genes inhibited MkP generation from HSCs. Subsequently, 9 candidate TFs, which include MZF1, GSX2, HOXC6, HES7, FOXB1, MXD3, HOXA9, NFATC1, and PCGF2, were identified to promote MkP generation from HSCs by lentivirus-mediated overexpression. Further analysis showed that MkP generation was increased by four-five fold with this TFs overexpression. To our knowledge, the functions of these 9 TFs in MK lineages development have not been reported previously. We also found inhibition of histone deacetylase (HDAC) activity could also promote the differentiation of HSCs into MkPs and platelets, possibly through regulating some of the 9 newly identified TFs: gene expression analysis showed GSX2, MXD3, HOXC6, and HES7 were significantly up-regulated while PCGF2, FOXB1, and MZF1 were moderately up-regulated after HDAC inhibition. These results have added more players into the regulatory network of endogenous factors during $\mathrm{MkP}$ development and platelet generation.

In another study to identify the exogenous signals, we found the neurotransmitter GABA was involved in the occurrence of platelets, indicating there is a link between the neural and hematopoietic systems (Zhu et al., 2019). We found GABRR1 is the only GABA receptor that is expressed in subsets of HSCs and MkPs. Electrophysiological recording experiment showed that GABRR1 ${ }^{+}$but not GABRR1 ${ }^{-}$ HSCs and MkPs respond to GABA in patch-clamp studies. Besides, GABA signaling through GABRR1 affected mouse HSC differentiating into megakaryocytic lineage cells. Stimulated by GABA agonists, including TACA and Muscimol, the mouse showed increased platelet numbers. We also found similar functions of GABRR1 in human hematopoiesis. Treatment with GABRR1 antagonist inhibited the number of MkPs and platelets generated from HSCs, while agonist treatment or overexpression of GABRR1 in HSCs significantly promoted MkP and platelet generation. Thus, this is the first study that showed the role of GABA signaling in the differentiation of HSCs and $\mathrm{MkPs}$, and provides another evidence for the correlation between the neural and hematopoietic systems. This study not only indicates GABA may be a potential target in plateletrelated disorders, but also shows it may help increase the MK and platelet production from HSCs (and potentially other stem cells) by adding GABA or its agonists during in vitro differentiation cultures.

Taken together, our studies reveal the complexity and the lack of knowledge of comprehensive $\mathrm{MK}$ regulators. Our laboratory is devoted to identifying more MK lineage-specific genes and signaling factors and completing the regulatory network of platelet generation, which may hopefully not only provide new drug targets related to platelet counts, activation, and aggregation, but also facilitate platelet generation in vitro. 


\section{DISCUSSION}

Currently, various methods have been developed and great progress has been made toward the generation of platelets from different cell types in vitro to fulfill the transfusion medicine purpose independent of or as a supplement to blood donations. However, certain limits still exist in using each of these cell types as the starting materials for platelet in vitro biogenesis, and these problems and/or questions must be resolved before they could be used in clinical applications.

Due to the rareness of HSCs in $\mathrm{PB}$ and the difficulty in obtaining $\mathrm{BM}$, HSCs from $\mathrm{CB}$ are now routinely used for in vitro platelet differentiation. Based on this, new cytokines (such as IL-11) and new chemical compounds (such as Y27632 and DAC) have been identified, a new 3D culture system (such as roller-bottle culture system), and new stromal cells (such as hTERT-transduced stroma) have been introduced to the culture conditions. These optimizations have significantly improved the differentiation efficacy, with $2 \times 10^{4}$ MKs obtained from 1 seeded $\mathrm{CD} 34^{+}$HSC, compared with the previous 5 MKs per HSC (Norol et al., 1998; Guan et al., $2020)$, and $1.26 \times 10^{11}-1.68 \times 10^{11}$ platelets generated from one $\mathrm{CB}$ unit, which equal to 2.5-3.4 units of donorderived platelets (Matsunaga et al., 2006). However, only a limited number of $\mathrm{CD} 34^{+} \mathrm{HSCs}$, about 3-5 $\times 10^{6}$, could be extracted from one unit of $\mathrm{CB}$, and these cells are difficult to obtain and culture. Besides, the number of platelets generated by current differentiation methods still cannot meet the requirement of transfusion medicine, therefore, more work is needed to improve the efficacy for large-scale generation of platelets in vitro. It has also been reported that, although $\mathrm{CB}$ HSCs were able to yield the highest number of MKs compared with those from $\mathrm{PB}$ and $\mathrm{BM}$, the $\mathrm{CB}$-derived $\mathrm{MKs}$ showed reduced ploidization indicating less maturation (van den Oudenrijn et al., 2000). Last but not least, there is no detailed analysis of the production of each progenitor population during the differentiation process, which led to the incomplete establishment of the differentiation path from HSCs to platelets.

Human embryonic stem cells and hiPSCs can proliferate indefinitely in vitro, which may bypass some limits associated with CB-derived HSCs as the starting materials. However, hESCs are derived from blastocyst-stage embryos (Thomson et al., 1998), so there are ethical controversies and potential risks of viral infection and congenital diseases in the human embryos. hiPSCs are derived from human somatic cells (Takahashi et al., 2007; Yu et al., 2007), thus avoid ethical controversy as in hESCs, but there are still some obstacles to use hiPSCs for in vitro generation of platelets, which include safety issues, long differentiation cycles, and the huge cost. One safety concern is the residual undifferentiated hiPSCs in the final products, as hiPSCs have the potential to form tumors after transplantation in vivo. Considering that a large number of platelets is needed for each transfusion (about $3 \times 10^{11}$ platelets per unit), even contamination of $0.01 \%$ hiPSCs in platelets means $3 \times 10^{7}$ undifferentiated hiPSCs in a treatment unit, which is more than enough to form tumors in human. Although platelet products are usually irradiated by gamma-ray before transfusion, one still cannot exclude the possibility of hiPSC contamination after irradiation. Another safety issue is that the oncogene c-MYC was overexpressed for the best results of platelet generation (Takayama et al., 2010; Nakamura et al., 2014; Ito et al., 2018), which leads to the risk of oncogenicity. Even though regulated by Doxycycline, the c-MYC gene may be reactivated in other ways. As for the production cycle, it takes weeks or even months to establish the hiPSC cell lines and carry out various assays to identify the best clones (Takahashi et al., 2007; Yu et al., 2007). Then, the differentiation of hiPSCs into platelets involves multiple steps and a long period. For example, in a study by Ito et al. (2018), it takes about 14 days to differentiate hiPSCs into hematopoietic progenitors in vitro, then several weeks to establish and expand imMKCLs by overexpression of c-MYC, BMI1, and BCL-XL, finally, another 6 days are needed to obtain mature platelets from these expanded imMKCLs. In another study by Feng et al. (2014), it takes 6 days to direct hiPSCs in vitro to hematopoietic progenitors, after which early MkPs were generated in another 7 days, a final 7 days are then required to induce mature MKs and platelet generation. The cost associated with hPSC-derived platelets is mainly due to the use of growth factors/small molecules and plasma/serum during the cell culture medium. Some growth factors like bFGF are indispensable in the routine culture of hPSCs, and more cytokines are needed in the platelet differentiation from these hPSCs. Ito et al. (2018) introduced human plasma/serum, SCF, TA-316, KP-457SR-1, GNF-351, and Y27632 at multiple stages of their differentiation method, and Feng et al. (2014) used even more cytokines, including BMP-4, VEGF, bFGF, TPO, SCF, Flt3-L, IL-3, IL-6, and IL-9. A common issue with both hESC- and hiPSC-derived platelets is, these generated platelets have a much shorter lifespan than those from plasma (Feng et al., 2014; Moreau et al., 2016), indicating these differentiated platelets are not as fully mature and functional as primary platelets.

Transdifferentiation from fibroblasts to platelets is not feasible for making large-scale platelets due to the limited sources, difficulty in expansion of fibroblasts, as well as low conversion efficiency (Ono et al., 2012; Pulecio et al., 2016). As to using adipose tissue-derived cells for in vitro platelet production, although expandable cell lines could be established from adipocytes, it is difficult to use these cells in large-scale manufacture because of their limited proliferation and inefficient differentiation. Moreover, the final products not only express typical platelets cell surface markers but also possess some features of mesenchymal stem cells, such as expression of CD90, indicating that these final products are not bona fide platelets, and the mechanism of adipocytes converting to platelets is still unknown (Tozawa et al., 2019).

In summary, although significant progress has been made toward the in vitro generation of platelets from HSCs, hPSCs, fibroblasts, and adipose-derived cells, with various stem cells as the most promising starting materials, the current issues of scalability, cost, duration of differentiation, and cell functionality 
are all hurdles to applying these in vitro generated platelets into clinical applications. A better understanding of the biology and development of megakaryocytes will hopefully address some of these issues and greatly facilitate in vitro platelet biogenesis on a large scale for transfusion medicine.

\section{AUTHOR CONTRIBUTIONS}

FZ contributed to the conception and design of the structure of the manuscript and wrote the first draft of the manuscript. HL collected information from reference literature, organized the database, and wrote some sections of the manuscript. FZ, HL, JL, and LW contributed to manuscript revision and read and approved the submitted version of the manuscript. All authors contributed to the article and approved the submitted version.

\section{REFERENCES}

Choi, E. S., Nichol, J. L., Hokom, M. M., Hornkohl, A. C., and Hunt, P. (1995). Platelets generated in vitro from proplatelet-displaying human megakaryocytes are functional. Blood. 85, 402-413. doi: 10.1182/blood.v85.2. 402.bloodjournal852402

Crispino, J. D., and Horwitz, M. S. (2017). GATA factor mutations in hematologic disease. Blood. 129, 2103-2110. doi: 10.1182/blood-2016-09-687889

Eicke, D., Baigger, A., Schulze, K., Latham, S. L., Halloin, C., Zweigerdt, R., et al. (2018). Large-scale production of megakaryocytes in microcarrier-supported stirred suspension bioreactors. Sci. Rep. 8:10146. doi: 10.1038/s41598-01828459-x

Feng, Q., Shabrani, N., Thon, J. N., Huo, H., Thiel, A., Machlus, K. R., et al. (2014). Scalable generation of universal platelets from human induced pluripotent stem cells. Stem cell Rep. 3, 817-831. doi: 10.1016/j.stemcr.2014.09.010

Gaur, M., Kamata, T., Wang, S., Moran, B., Shattil, S. J., and Leavitt, A. D. (2006). Megakaryocytes derived from human embryonic stem cells: a genetically tractable system to study megakaryocytopoiesis and integrin function. J. Thromb. Haemost. 4, 436-442. doi: 10.1111/j.1538-7836.2006. 01744.x

Goldfarb, A. N. (2009). Megakaryocytic programming by a transcriptional regulatory loop: a circle connecting RUNX1, GATA-1, and P-TEFb. J Cell Biochem. 107, 377-382. doi: 10.1002/jcb.22142

Guan, X., Qin, M., Zhang, Y., Wang, Y., Shen, B., Ren, Z., et al. (2017). Safety and efficacy of megakaryocytes induced from hematopoietic stem cells in murine and nonhuman primate models. Stem Cells Transl. Med. 6, 897-909. doi: 10.5966/sctm.2016-0224

Guan, X., Wang, L., Wang, H., Wang, H., Dai, W., and Jiang, Y. (2020). Good manufacturing practice-grade of megakaryocytes produced by a novel ex vivo culturing platform. Clin. Transl. Sci. 13, 1115-1126. doi: 10.1111/cts. 12788

Harrison, P. (2005). Platelet function analysis. Blood Rev. 19, 111-123. doi: 10.1016/ j.blre.2004.05.002

Ito, Y., Nakamura, S., Sugimoto, N., Shigemori, T., Kato, Y., Ohno, M., et al. (2018). Turbulence activates platelet biogenesis to enable clinical scale ex vivo production. Cell 174, 636-648.e18. doi: 10.1016/j.cell.2018.06.011

Li, Y., Luo, H., Liu, T., Zacksenhaus, E., and Ben-David, Y. (2015). The ets transcription factor Fli-1 in development, cancer and disease. Oncogene 34, 2022-2031. doi: 10.1038/onc.2014.162

Lu, S. J., Li, F., Yin, H., Feng, Q., Kimbrel, E. A., Hahm, E., et al. (2011). Platelets generated from human embryonic stem cells are functional in vitro and in the microcirculation of living mice. Cell Res. 21, 530-545. doi: 10. $1038 / \mathrm{cr} .2011 .8$

Machlus, K. R., and Italiano, J. E. (2013). The incredible journey: From megakaryocyte development to platelet formation. J. Cell Biol. 201, 785-796. doi: $10.1083 /$ jcb.201304054

Matsubara, Y., Saito, E., Suzuki, H., Watanabe, N., Murata, M., and Ikeda, Y. (2009). Generation of megakaryocytes and platelets from human subcutaneous

\section{FUNDING}

This study was supported by Shanghai Municipal Education Commission (ZXWF082101) and the Double First-Class Initiative startup research fund (WF220408222) to FZ from Shanghai Jiao Tong University.

\section{ACKNOWLEDGMENTS}

The authors thank colleagues for discussion during the preparation of this manuscript. They would also like to thank all the researchers, cited or not, that contributed to progress related to the discussed topic in this manuscript. Due to space limitations, the authors were not able to list all related references in this manuscript.

adipose tissues. Biochem. Biophys. Res. Commun. 378, 716-720. doi: 10.1016/j. bbrc.2008.11.117

Matsunaga, T., Tanaka, I., Kobune, M., Kawano, Y., Tanaka, M., Kuribayashi, K., et al. (2006). Ex vivo large-scale generation of human platelets from cord blood CD34+ cells. Stem Cells 24, 2877-2887. doi: 10.1634/stemcells.2006-0309

McArthur, K., Chappaz, S., and Kile, B. T. (2018). Apoptosis in megakaryocytes and platelets: the life and death of a lineage. Blood 131, 605-610. doi: 10.1182/ blood-2017-11-742684

Moreau, T., Evans, A. L., Vasquez, L., Tijssen, M. R., Yan, Y., Trotter, M. W., et al. (2016). Large-scale production of megakaryocytes from human pluripotent stem cells by chemically defined forward programming. Nat. Commun. 7:11208. doi: $10.1038 /$ ncomms 11208

Nakamura, S., Takayama, N., Hirata, S., Seo, H., Endo, H., Ochi, K., et al. (2014). Expandable megakaryocyte cell lines enable clinically applicable generation of platelets from human induced pluripotent stem cells. Cell stem cell. 14, 535-548. doi: 10.1016/j.stem.2014.01.011

Nakeff, A., and Maat, B. (1974). Separation of megakaryocytes from mouse bone marrow by velocity sedimentation. Blood 43, 591-595. doi: 10.1182/blood.v43. 4.591 .591

Norbnop, P., Ingrungruanglert, P., Israsena, N., Suphapeetiporn, K., and Shotelersuk, V. (2020). Generation and characterization of HLA-universal platelets derived from induced pluripotent stem cells. Sci. Rep. 10:8472. doi: 10.1038/s41598-020-65577-x

Norol, F., Vitrat, N., Cramer, E., Guichard, J., Burstein, S. A., Vainchenker, W., et al. (1998). Effects of cytokines on platelet production from blood and marrow CD34+ cells. Blood 91, 830-843. doi: 10.1182/blood.v91.3.830.830_830_843

Ono, Y., Wang, Y., Suzuki, H., Okamoto, S., Ikeda, Y., Murata, M., et al. (2012). Induction of functional platelets from mouse and human fibroblasts by $\mathrm{p} 45 \mathrm{NF}-$ E2/Maf. Blood 120, 3812-3821. doi: 10.1182/blood-2012-02-413617

Pick, M., Azzola, L., Osborne, E., Stanley, E. G., and Elefanty, A. G. (2013). Generation of megakaryocytic progenitors from human embryonic stem cells in a feeder- and serum-free medium. PLoS One. 8:e55530. doi: 10.1371/journal. pone.0055530

Proulx, C., Dupuis, N., St-Amour, I., Boyer, L., and Lemieux, R. (2004). Increased megakaryopoiesis in cultures of CD34-enriched cord blood cells maintained at 39 degrees C. Biotechnol. Bioeng. 88, 675-680. doi: 10.1002/bit.20288

Pulecio, J., Alejo-Valle, O., Capellera-Garcia, S., Vitaloni, M., Rio, P., MejiaRamirez, E., et al. (2016). Direct conversion of fibroblasts to megakaryocyte progenitors. Cell Rep. 17, 671-683. doi: 10.1016/j.celrep.2016.09.036

Robb, L., and Begley, C. (1997). The SCL/TAL1 gene: roles in normal and malignant haematopoiesis. Bioessays 19, 607-613. doi: 10.1002/bies.950190711

Seita, J., Sahoo, D., Rossi, D. J., Bhattacharya, D., Serwold, T., Inlay, M. A., et al. (2012). Gene expression commons: an open platform for absolute gene expression profiling. PLoS One. 7:e40321. doi: 10.1371/journal.pone.0040321

Seita, J., and Weissman, I. L. (2010). Hematopoietic stem cell: self-renewal versus differentiation. Wiley Interdisc. Rev. Syst. Biol. Med. 2, 640-653. doi: 10.1002/ wsbm. 86 
Squires, J. E. (2015). Indications for platelet transfusion in patients with thrombocytopenia. Blood Transfus. 13, 221-226. doi: 10.2450/2014.0105-14

Suzuki, D., Flahou, C., Yoshikawa, N., Stirblyte, I., Hayashi, Y., Sawaguchi, A., et al. (2020). iPSC-derived platelets depleted of HLA class I are inert to antiHLA class I and natural killer cell immunity. Stem Cell Rep. 14, 49-59. doi: 10.1016/j.stemcr.2019.11.011

Takahashi, K., Tanabe, K., Ohnuki, M., Narita, M., Ichisaka, T., Tomoda, K., et al. (2007). Induction of pluripotent stem cells from adult human fibroblasts by defined factors. Cell 131, 861-872. doi: 10.1016/j.cell.2007.11.019

Takayama, N., Nishikii, H., Usui, J., Tsukui, H., Sawaguchi, A., Hiroyama, T., et al. (2008). Generation of functional platelets from human embryonic stem cells in vitro via ES-sacs, VEGF-promoted structures that concentrate hematopoietic progenitors. Blood 111, 5298-5306. doi: 10.1182/blood-2007-10-117622

Takayama, N., Nishimura, S., Nakamura, S., Shimizu, T., Ohnishi, R., Endo, H., et al. (2010). Transient activation of c-MYC expression is critical for efficient platelet generation from human induced pluripotent stem cells. J. Exp. Med. 207, 2817-2830. doi: 10.1084/jem.20100844

Thomson, J. A., Itskovitz-Eldor, J., Shapiro, S. S., Waknitz, M. A., Swiergiel, J. J., Marshall, V. S., et al. (1998). Embryonic stem cell lines derived from human blastocysts. Science 282, 1145-1147. doi: 10.1126/science.282.5391.1145

Tozawa, K., Ono-Uruga, Y., Yazawa, M., Mori, T., Murata, M., Okamoto, S., et al. (2019). Megakaryocytes and platelets from a novel human adipose tissuederived mesenchymal stem cell line. Blood 133, 633-643. doi: 10.1182/blood2018-04-842641

Tu, Q., Liu, C. C., Wu, D., and Pei, S. U. (2017). Establishment of the screening model for highly efficient generation of megakaryocytes and platelets from human pluripotent stem cells (in Chinese). Sci. Sin. Vitae 47, 1363-1374. doi: 10.1360/N052017-00270

van den Oudenrijn, S., von dem Borne, A. E., and de Haas, M. (2000). Differences in megakaryocyte expansion potential between $\mathrm{CD} 34(+)$ stem cells derived from cord blood, peripheral blood, and bone marrow from adults and children. Exp. Hematol. 28, 1054-1061. doi: 10.1016/s0301-472x(00)00517-8

Wang, H., Liu, C., Liu, X., Wang, M., Wu, D., Gao, J., et al. (2018). MEIS1 regulates hemogenic endothelial generation, megakaryopoiesis, and thrombopoiesis in human pluripotent stem cells by targeting TAL1 and FLI1. Stem Cell Rep. 10, 447-460. doi: 10.1016/j.stemcr.2017.12.017

Wang, H., Yang, Y., Liu, J., and Qian, L. (2021). Direct cell reprogramming: approaches, mechanisms and progress. Nat. Rev. Mol. Cell Biol. 22, 410-424. doi: 10.1038/s41580-021-00335-z
Yang, Y., Liu, C., Lei, X., Wang, H., Su, P., Ru, Y., et al. (2016). Integrated biophysical and biochemical signals augment megakaryopoiesis and thrombopoiesis in a three-dimensional rotary culture system. Stem Cells Transl. Med. 5, 175-185. doi: 10.5966/sctm.2015-0080

Yu, J., Vodyanik, M. A., Smuga-Otto, K., Antosiewicz-Bourget, J., Frane, J. L., Tian, S., et al. (2007). Induced pluripotent stem cell lines derived from human somatic cells. Science 318, 1917-1920. doi: 10.1126/science.1151526

Zeddies, S., Jansen, S. B., di Summa, F., Geerts, D., Zwaginga, J. J., van der Schoot, C. E., et al. (2014). MEIS1 regulates early erythroid and megakaryocytic cell fate. Haematologica 99, 1555-1564. doi: 10.3324/haematol.2014.106567

Zhang, L., Liu, C., Wang, H., Wu, D., Su, P., Wang, M., et al. (2018). Thrombopoietin knock-in augments platelet generation from human embryonic stem cells. Stem Cell Research Therapy. 9:194. doi: 10.1186/s13287-018-0926-x

Zhu, F., Feng, M., Sinha, R., Murphy, M. P., Luo, F., Kao, K. S., et al. (2019). The GABA receptor GABRR1 is expressed on and functional in hematopoietic stem cells and megakaryocyte progenitors. Proc. Natl. Acad. Sci. U.S.A. 116, 18416-18422. doi: 10.1073/pnas.1906251116

Zhu, F., Feng, M., Sinha, R., Seita, J., Mori, Y., and Weissman, I. L. (2018). Screening for genes that regulate the differentiation of human megakaryocytic lineage cells. Proc. Natl. Acad. Sci. U.S.A. 115, E9308-E9316. doi: 10.1073/pnas. 1805434115

Conflict of Interest: The authors declare that the research was conducted in the absence of any commercial or financial relationships that could be construed as a potential conflict of interest.

Publisher's Note: All claims expressed in this article are solely those of the authors and do not necessarily represent those of their affiliated organizations, or those of the publisher, the editors and the reviewers. Any product that may be evaluated in this article, or claim that may be made by its manufacturer, is not guaranteed or endorsed by the publisher.

Copyright (c) $2021 \mathrm{Liu}, \mathrm{Liu}$, Wang and Zhu. This is an open-access article distributed under the terms of the Creative Commons Attribution License (CC BY). The use, distribution or reproduction in other forums is permitted, provided the original author(s) and the copyright owner(s) are credited and that the original publication in this journal is cited, in accordance with accepted academic practice. No use, distribution or reproduction is permitted which does not comply with these terms. 